\title{
Effect of Simvastatin on 5-HT and 5-HTT in a Rat Model of Pulmonary Artery Hypertension
}

\author{
Xue Jiang ${ }^{\mathrm{a}}$ LinDong Yuan ${ }^{\mathrm{a}}$ Peng Lia Jia Wang ${ }^{\mathrm{a}}$ Pengyu Wang ${ }^{\mathrm{a}}$ Lihai Zhang ${ }^{\mathrm{a}}$ \\ Bojian Sun ${ }^{b}$ Wuzhuang Sun ${ }^{a}$
}

${ }^{a}$ Department of Respiration, the First Hospital of Hebei Medical University, Shijiazhuang, ${ }^{b}$ Department of Rheumatology, the First Hospital of Hebei Medical University, Shijiazhuang, China

\section{Key Words}

Pulmonary artery hypertension $\cdot$ Serotonin $\cdot$ Simvastatin

\begin{abstract}
Background/Aims: To investigaterole of serotonin (5-HT) and serotonin transporter (5-HTT) in a rat model of cigarette smoke-induced pulmonary artery hypertension (PAH) and the effect of statins on regulating 5HT and 5-HTT. Methods: A rat model of COPD comorbid with $\mathrm{PAH}$ was established by cigarette smoke exposure with or without simvastatin administration. The smoking and the simvastatin plus smoking groups were exposed to cigarette smoke daily, and the latter received simvastatin at $5 \mathrm{mg} / \mathrm{kg}$, once a day. After 16 weeks of cigarette smoke exposure, body weight and mean pulmonary arterial pressure (mPAP) were measured, bronchoalveolar lavage (BAL) was performed, and lung tissues and blood samples were collected to determine cardiopulmonary pathology, physiological indices, blood levelof 5-HT and expression of 5-HTT in the lung. Results: In addition to alveolar structural damage (COPD-like injury), chronic cigarette smoke exposure lead to pulmonary artery remodeling and PAH as evidenced by significant elevation of mPAP, RVHI, WT\%and WA\%. Cigarette smoke exposure resulted in significant reduction in animal body weight, and simvastatin significantly prevented smoke-induced weight loss. The number of inflammatory cells in BALF was dramatically increased in smoke exposed rats, and simvastatin dampened the number of leukocytes, neutrophils, lymphocytes, and macrophages. In addition, circulating 5-HTand expression of 5-HTT in the lung were significantly increased in the smoked rats compared to control rats, and it was significantly reduced by simvastatin. Alteration of BALF inflammatory cells, 5-HT and 5-HTT was significantly correlated with changes of MPAP, RVHI, WT\% and WA\%. Conclusions: Cigarette smoke exposure could result in not only COPD, but also PAH, which may attribute to the alteration of blood $5-\mathrm{HT}$ and lung tissue $5-\mathrm{HTT}$. Simvastatin could significantly inhibited 5-HT and 5-HTT expression, and by which mechanism, it may protect animals from development of PAH.
\end{abstract}

$X$. Jiang and L. Yuan contributed equally to the work.

Wuzhuang Sun

KARGER 125
Department of Respiration, the First Hospital of Hebei Medical University; 89 Donggang Road, Shijiazhuang, 050031, (China)

Tel. +8618633889856, E-Mail swzhg@126.com or wzsun@hotmail.com 


\section{Cellular Physiology Cell Physiol Biochem 2015;37:1712-1724 \begin{tabular}{l|l} 
and Biochemistry Published online: November 09, 2015 & $\begin{array}{l}\text { Co 2015 S. Karger AG, Basel } \\
\text { www.karger.com/cpb }\end{array}$ \\
\hline
\end{tabular} \\ Jiang et al.: Effect of Simvastatin on 5-HT and 5-HTT}

\section{Introduction}

Pulmonary artery hypertension (PAH) is the clinical term used to describe a rare condition associated with progressive elevation of pulmonary arterial pressure (larger or equal $25 \mathrm{~mm} \mathrm{Hg}$ at rest or $30 \mathrm{~mm} \mathrm{Hg}$ in exercise). In the last 30 years, research in PAH has dramatically increased survival time and quality of life for patients with PAH [1]. However, there remains no cure despite major advances in understanding of the pathogenesis of $\mathrm{PAH}$ with respect to genetics [2], inflammation [3], and cellular and molecular biology [4]. PAH is associated with pulmonary vascular remodeling [5], which occurs more commonly secondary to collagen vascular disease, congenital systemic to pulmonary shunt, chronic obstructive pulmonary disease (COPD), interstitial fibrosis and high left-sided filling pressures[6, 7]. The earliest pathological alteration of PAH is muscularization of the terminal portion of pulmonary arterialole. The chronic hypoxia rat is a commonly studied model of pulmonary hypertension [8, 9]. However, to our knowledge, cigarette smoke-induced PAH has not been reported.

Smoking derived substances and chemicals are harmful, and can cause airway and vasculature inflammatory responses, which ultimately result in endothelial cell damage, pulmonary vascular remodeling, and pulmonary hypertension following COPD and emphysema. Therefore, the current study was designed to investigate PAH following cigarette smoke exposure in rats.

Long-term smoking exposure result in infiltration of inflammatory cells into the lung tissues including vasculature adventitia, which initiates vascular injury and remodeling through stimulating release of blood vessel activating factors including 5-hydroxytryptamine (5-HT), endothelin (ET-1), and many other factors [10]. 5-HT is mainly secreted by gastrointestinal chromaffin cells, serotinergic neurons, pulmonary neuroendocrine cells and activated platelets. Nerve endothelial corpuscles that are located in the airway could also secrete 5-HT [11]. Increasing evidence has shown that 5-HT is an important factor in the development of $\mathrm{PAH}$, which can singularly or synergistically (with other factors) induce the contraction of pulmonary arteries, proliferation of pulmonary arterial smooth muscle cells (PASMCs), and local micro thrombus formation. In this regard, 5-HT induced mitotic responses of PASMCs, which is mediated by mitogen activated protein kinase (MAPK)dependent pathways [12], and links the signal transduction between the surface receptor and the expression of target genes to modulate cell proliferation, differentiation, and apoptosis. Studies also suggest that 5-HT induced mitogenesis in PASMCs requires cellular internalization of 5-HT through the 5-HT transporter (5-HTT) rather than binding to a membrane receptor $[13,14]$.

Studies have also indicated that hyperplasia of pulmonary artery smooth muscle cells in primary or secondary PAH is attributed to the overexpression of the serotonin transporter (5HTT) [15]. The 5-HTT is a membrane protein whose main function is transporting 5-HT into the cells. Recent studies found that 5-HTT in PASMCs exerted multiple properties, including transporting 5-HT to induce proliferation of PASMCs [16]. Studies have shown that 5-HTT expression in PASMCs of primary PAH patients was markedly increased, and considered 5-HT play an important role in the development of PAH [17]. Following entry of 5-HT into the cells through 5-HTT, the MAPK pathway is activated to modulate the phosphorylation of GTPase activating proteins (GAP), enhance the activity of Ras, and induce DNA synthesis [18].

Simvastatin is an HMG-CoA reductase inhibitor that blocks production of cholesterol. In addition to their hypolipidemic effects, statins have variety of biological effects including amelioration of endothelial cell function; stimulation of endothelial nitric oxide synthase (eNOS) expression in vascular endothelial cells; anti-inflammation; and inhibition of smooth muscle cell proliferation [19]. Both in vivo and in vitro studies have demonstrated the antiinflammatory and immuno-regulatory properties of statins [20-22]. Previous studies have reported that simvastatin reverses pulmonary vascular remodeling in PAH animal models, although the mechanisms remain unclear. A non-randomized and controlled clinical study 
reported that simvastatin ameliorated symptoms in PAH patients [23].Other investigators have observed that statins dampened the rise in PAH by inhibiting the hyperplasia of rat PASMCs [24], and that statins had therapeutic benefit and improved prognosis of patients with pulmonary hypertension [23].It has also been reported that statin administration could change serotonergic pathway signaling in the central nervous system and it linked to the expression and activity of the 5-HTT [25].

In the current study, therefore, cigarette smoke-induced rat PAH model was established and effect of simvastatin on smoking-induced rat PAH was investigated. Specifically, level of plasma 5-HT and lung tissue 5-HTT expression were determined in the PAH model, and their correlationwith alteration of parameters of PAH including mean pulmonary artery pressure (mPAP), right ventricular hypertrophy index (RVHI), small artery wall thickness (WT\%), and small artery wall area (WA\%) were determined.

\section{Materials and Methods}

Animals and cigarette smoke exposure

Healthy male SD rats, 6 weeks old, body weight $100 \pm 20$ g, were maintained in the animal facilities, Hebei Medical University. Animals were accommodated for one week before the experiment. All procedures were in accordance with the institutional and national guidelines for the care and use of laboratory animals. The Study Protocol was approved by The Institutional Animal Care and Use Committee, Hebei Medical University. Animals were randomized into the following three groups (10 rats in each group): Control group, Smoking group and Smoking + simvastatin group. Rats in the groups of smoking only or smoking + simvastatin were exposed to cigarette smoke in a smoking device manufactured by Shijiazhuang Jinyang Science and Technology Inc. (model: JY-01, Shijiazhuang, Hebei, China). Briefly, 20 cigarettes were burnt continuously and blown into a box together with oxygen, and animals were whole-body exposed to the cigarette smoke in the box. Animals were exposed to the cigarette smoke for one hour each time, twice a day, 5 days a week for 16 weeks. Animals of smoking + simvastatin group were intragastrically administered simvastatin (MSD, Hangzhou, China) at a dose of $5 \mathrm{mg} / \mathrm{kg} /$ day, each day prior to the smoke exposure. The control rats were not treated with any reagent.

\section{Parameters of pulmonary arterial hypertension}

Pulmonary arterial pressure (PAP) measurement. Under anesthesia, the right external carotid artery was exposed and a heparinized catheter was inserted into the right external carotid artery and advanced till pulmonary artery to obtain pulmonary artery pressure (PAP), which was recorded by a multichannel recorder through a pressotransducer. Mean of PAP (mPAP) was calculated.

The right ventricular hypertrophy index (RVHI). This was done by detaching and weighing the right ventricular free wall (RV) followed by calculating the right ventricular hypertrophy index (RVHI) $=[\mathrm{RV}$ / $(\mathrm{LV}+\mathrm{S})]$. Briefly, right ventricular wall was free from its atrial, septal and valve ring attachments, and pericardial fat was carefully removed. The right ventricular wall (RV) was then flattened out (endocardial surface down) and blotted on a filter paper for mass determination by weight. The left ventricle, including septum (S) was similarly weighed after removal of atrial and valvular attachments and pericardial fat $(\mathrm{LV}+\mathrm{S})$. A right ventricular hypertrophy index (RVHI) was then calculated as shown above.

Percentage of wall thickness (WT \%) and wall area (WA \%). Select one HE-stained slide from each rat, and pick 15 small pulmonary arteries, which was less than $50 \mu \mathrm{m}$ in external diameter; 15 medium pulmonary arteries (between 50-150 $\mu \mathrm{m}$ in external diameter); and 10 integrated arteries, measure the total area (TA) and inner-side area (IA) of the arteries, wall thickness (WT), and external diameter (ED). WT $\%$ and WA $\%$ were then calculated as following:

WT $\%=(2 \times \mathrm{WT} / \mathrm{ED}) \times 100 \%$,

WA $\%=(T A-I A) / T A \times 100 \%$.

Bronchoalveolar LavageFluid (BALF) collection and analysis

Bronchoalveolar lavage was performed using a three-in/three-out pattern of intra-tracheal instillation and removal with a total volume of $3 \mathrm{~mL}$ of saline in order to enrich total cells and optimize protein recovery. 


\section{Cellular Physiology Cell Physiol Biochem 2015;37:1712-1724

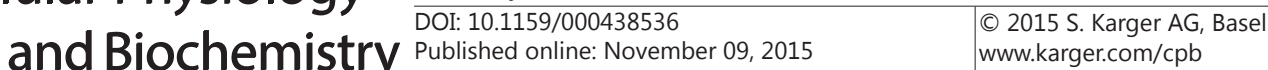 \\ Jiang et al.: Effect of Simvastatin on 5-HT and 5-HTT}

BALF specimens were centrifuged at $1000 \mathrm{rpm}$ x $10 \mathrm{~min}$. Pelleted cells were re-suspended with PBS, and differentially counted by Wright-Giemsa staining. Total of 200 leukocytes was counted in each BALF sample, and percentage of macrophage, neutrophil, and lymphocyte was calculated.

Total leukocytes number in BALF = leukocytes number $(/ \mathrm{mL}) \times$ volume of BALF $(\mathrm{mL})$.

\section{5-Hydroxytryptamine (5-HT) quantification by ELISA}

Plasma 5-hydroxytryptamine (5-HT) level was quantified by ELISA using a commercially available kit (Walnut, CA, USA), following the manufacturer's instruction.

Immunohistochemistry

Expression of serotonin transporter (5-HTT) in rat lung was assessed by immunohistochemistry. Briefly, paraffin embedded lung tissue slice was de-paraffinized and hydrated. Antigen was retrieved using sodium citrate and with heat-induced retrieval. Anti-5-HTT antibody at 1:200 dilution (ZHGB-BIO, Beijing, China) was applied overnight at $4^{\circ} \mathrm{C}$. After HRP-conjugated $2^{\text {nd }}$ antibody was applied, expression of 5-HTT was visualized using a DAB detection kit (CWBIO (Beijing, China).

\section{Real time RT-PCR}

Total RNA was extracted from rat lung tissues with Trizol reagent (SBS, Shanghai, China) following the manufacturer's instruction. After RNA quantification, $1 \mu \mathrm{g}$ total RNA was used for reverse transcription using high capacity reverse transcription kit (Applied Biosystem by Life Technology, Grand Island, NY, USA). Quantitative real time PCR was performed using primers/probe and reaction reagents, 7500 Gene Detection System (Applied Biosystem by Life Technology, Grand Island, NY, USA). ß-actin was used as internal control. Data expressed as fold change versus Control, using $2^{(-\Delta \Delta C t)}$ method.

\section{Statistical analysis}

All data were analyzed by SPSS 13.0 statistical software, and presented as mean \pm SD. One-way ANOVA was used for comparison of multiple groups, and Dunnett'sT-test was used for comparison of paired groups. Correlation analysis was conducted between the indices by logistic regression analysis, and it was considered statistically significant when $p<0.05$.

\section{Results}

\section{Body weight alteration}

There was no differencein baseline body weight among the three groups ( $p>0.05)$. After 16 weeks of smoke exposure, however, body weightwas significantly reduced in the smokeexposed ratscompared to the control rats (449 \pm 15 vs $489 \pm 17 \mathrm{~g}, p<0.01)$. Simvastatin significantly prevented smoke-induced weight loss (470 $\pm 11 \mathrm{~g}, p<0.01$ compared to the smoking group, Table 1).

\section{Parameters of pulmonary arterial hypertension}

Establishment of rat pulmonary hypertension model was demonstrated by the following three parameters.

Pulmonary arterial pressure (PAP). Compared to the control group (17.37 $\pm 0.87 \mathrm{mmHg})$, mPAP was significantly increased in the smoking group $(29.97 \pm 1.11 \mathrm{mmHg}, p<0.01)$, and it was significantly blocked by simvastatin $(20.69 \pm 1.19 \mathrm{mmHg}, p<0.01$, Fig. $1 \mathrm{~A})$.

Right ventricular hypertrophy index (RVHI). Consistent with the change of mPAP, cigarette smoking significantly increased RVHI $(0.223 \pm 0.011$ of smoking rat vs 0.199 \pm 0.009 of control, $p<0.01$ ), and simvastatin could significantly reduce smoking-induced increase of RVHI $(0.208 \pm 0.007, p<0.01$, Fig. 1B).

Table 1. Alteration of body weight (mean \pm SD, $\mathrm{N}=10$ ). ${ }^{* *} p<0.01$ compared to control group; ${ }^{\Delta \Delta} p<0.01$ compared to smoking group

\begin{tabular}{lcc}
\hline Groups & Baseline (g) & Post-smoking (g) \\
\hline Control & $102 \pm 7$ & $489 \pm 17$ \\
Smoking & $101 \pm 7$ & $449 \pm 15^{* *}$ \\
Statins & $102 \pm 6$ & $470 \pm 11^{* * \Delta \Delta}$ \\
\hline
\end{tabular}




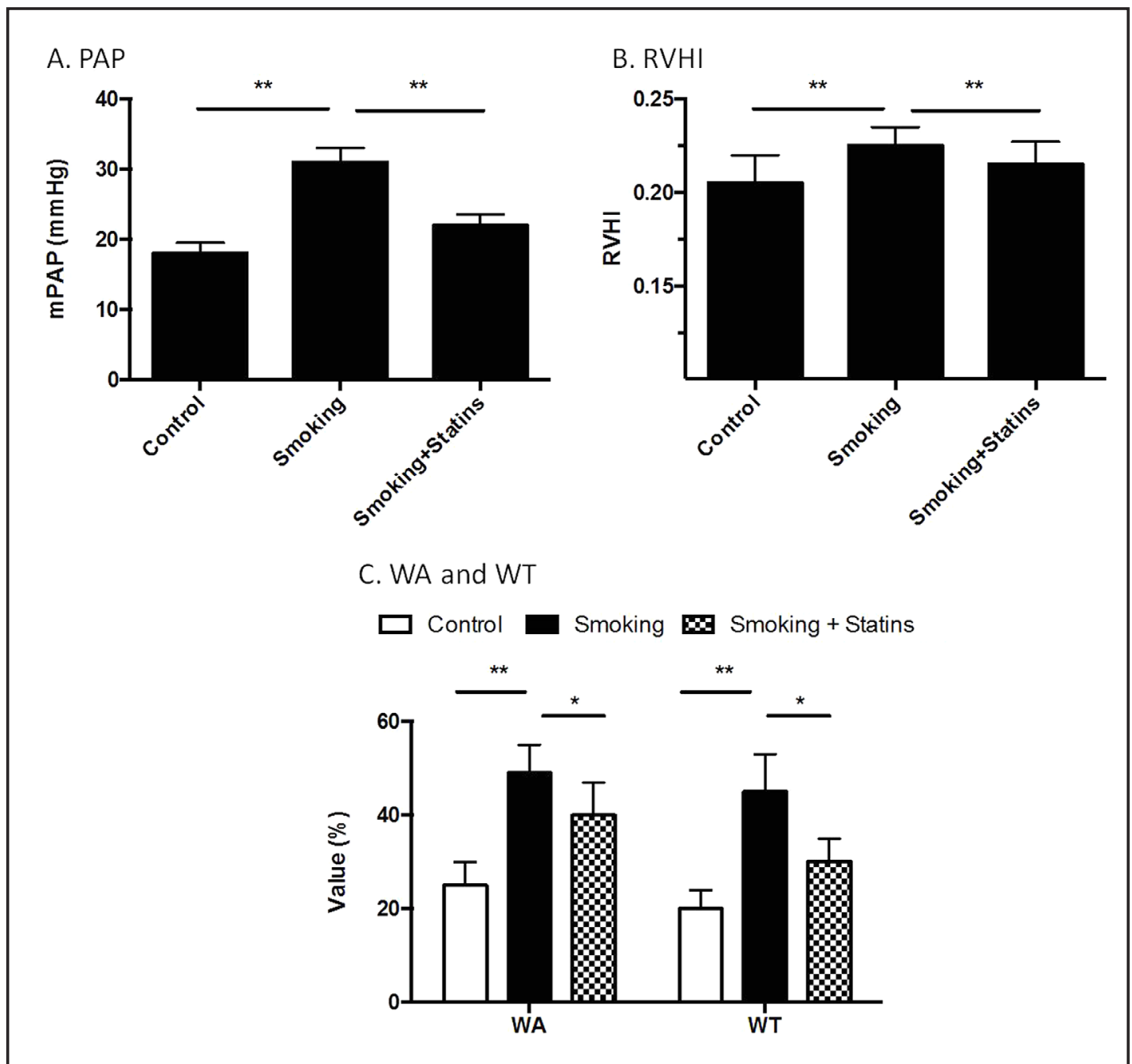

Fig. 1. PAH model parameters. (Panel A) Mean pulmonary artery pressure (mPAP). Mean pulmonary artery pressure was measured as described in the methods. Vertical axis: mPAP (mmHg); horizontal axis: treatment. (Panel B) Right ventricular hypertrophy index (RVHI). RVHI was measured as described in the methods. Vertical axis: arbitrary number of RVHI; horizontal axis: treatment. (Panel C) Percentage of vascular wall area (WA \%) and wall thickness (WT\%). Vertical axis: Percentage (\%); horizontal axis: vascular wall area or wall thickness. ${ }^{* *} p<0.01 ;{ }^{*} p<0.05$. Data presented was an average of 10 biological replicates for each treatment group.

Wall thickness (WT \%) and wall area (WA \%). Compared to the control group, WT\% and WA\% were significantly increased in the smoking group (37.4 \pm 8.5 and $48.8 \pm 7.5$, respectively) compared to control group (20.3 \pm 5.0 and $24.8 \pm 4.6$, respectively, $p<0.01)$. Simvastatin could significantly protected vascular wall from cigarette smoke-induced increase of thickness and area (30.3 \pm 8.9 and $40.8 \pm 9.8$, respectively, $p<0.05$ as compared to the smoking group, Fig. 1C).

BALF total and differential cell count, and its correlationship with parameters of PAH

Fluid recovered from bronchoalveolar lavage was $78 \pm 8 \%, 77 \pm 7 \%$, and $77 \pm 9 \%$ of injected volume in control group, smoking group and smoking plus simvastatin group, respectively, and there was no significant difference between the 3 groups $(p>0.05)$. As expected, number of total white blood cells was significantly increased in the BALF of smoking group ( $24.89 \pm 1.47 \times 10^{6}$ cells/L vs $20.82 \pm 1.23 \times 10^{6}$ cells/L of control, $\left.p<0.01\right)$, and it was significantly reduced in the rats treated with simvastatin $\left(22.56 \pm 1.76 \times 10^{6}\right.$ cells $/ \mathrm{L}, p<$ 
Fig. 2. BALF total and differential cell count. BALF was harvested, and total white blood cells (WBC) and differential cell count (neutrophil, macrophage, and lymphocyte) was performed as described in the methods. Vertical axis: the number of cells $\left(\times 10^{6} / \mathrm{L}\right)$ in BALF; horizontal axis: total and differentially counted cell type. ${ }^{* *} p<0.01 ;{ }^{*} p<0.05$. Data presented was an average of 10 biological replicates for each group.

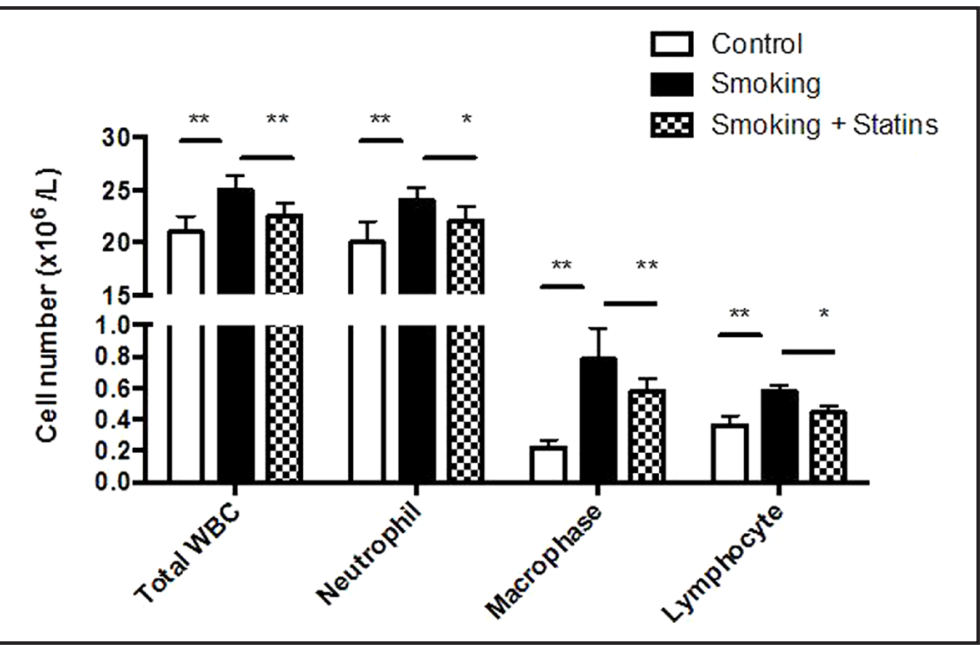

A.

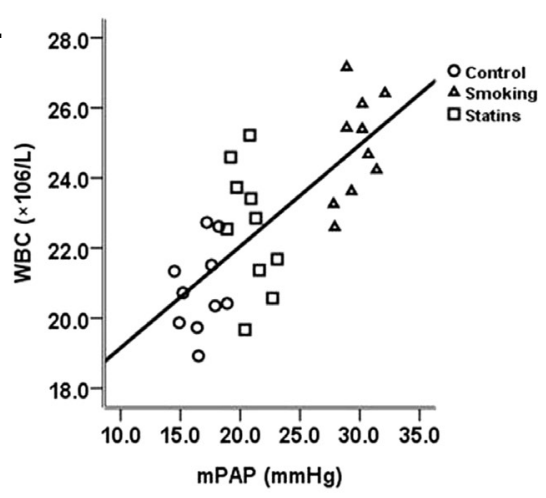

C.

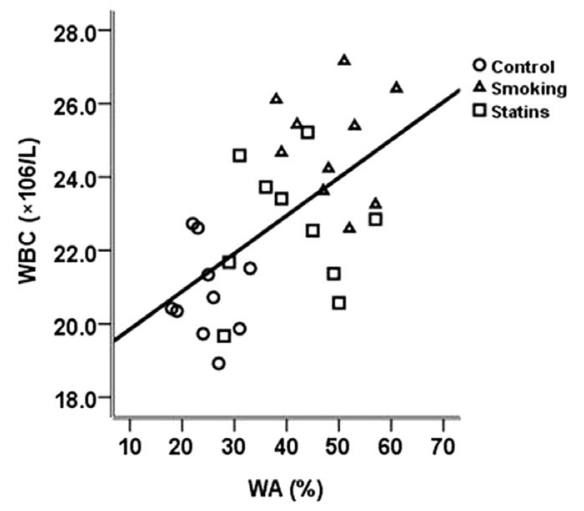

B.

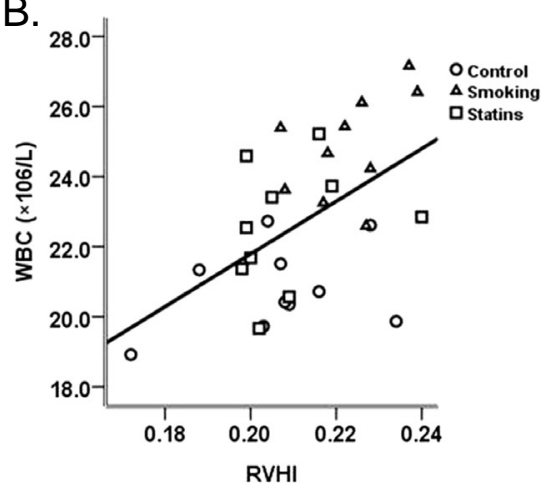

D.

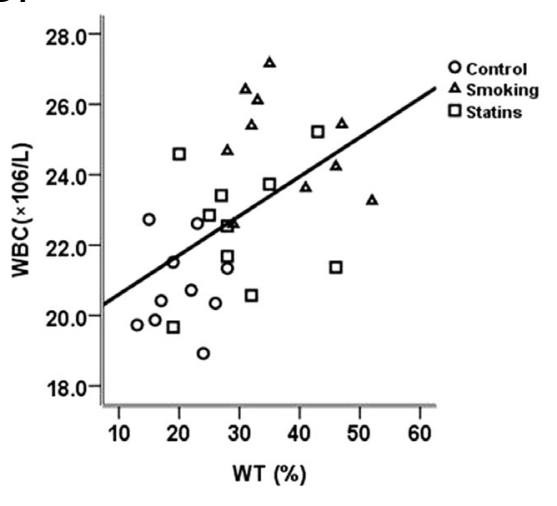

Fig. 3. Correlation between WBC count and PAP, RVHI, WA\%, and WT\%. (Panel A) Positive correlation between number of WBC and mPAP $(r=0.739, p=0.000)$. (Panel B) Positive correlation between number of WBC and RVHI $(r=0.524, p=0.003)$. (Panel C) Positive correlation between number of WBC and WA $\%(r=$ $0.581, p=0.001)$. (Panel D) Positive correlation between number of WBC and WT\% $(r=0.514, p=0.004)$. $\mathrm{N}=10$ rats each group.

0.01, Fig. 2). Furthermore, differential count of neutrophils, macrophages and lymphocytes revealed that cigarette smoke exposure resulted in significantly increased accumulation of neutrophils, macrophages and lymphocytes in the bronchial alveolar lavage $(p<0.01)$, and that simvastatin significantly reduced smoke-induced inflammatory cell accumulation in the BALF $(p<0.05$ or 0.01 , Fig. 2$)$.

\section{KARGER}


A. Control

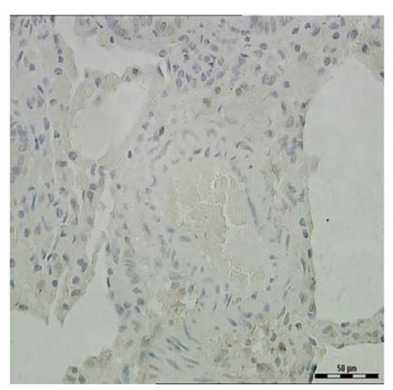

B. Smoking

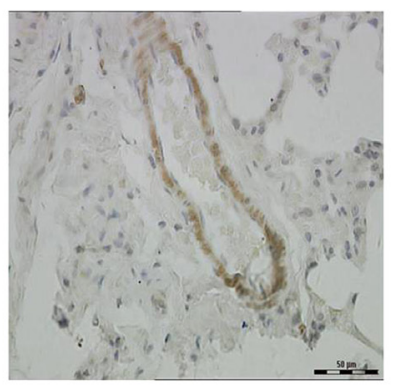

C. Smoking + Statins

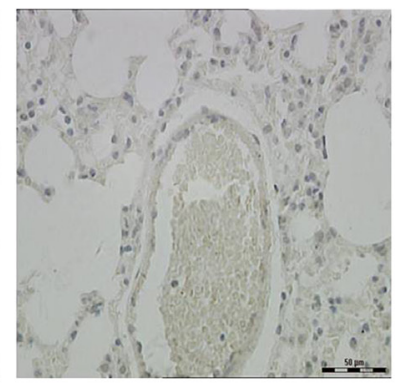

Fig. 4. Expression of 5-HTT in lung tissue. Rat lung tissues were immunostained for 5-HTT as described in the methods. (Panel A) Control group. (Panel B) Smoke-exposed group. (Panel C) Simvastatin group. Data presented was one representative of 10 biological replicates. Magnification: x400.

A. mRNA

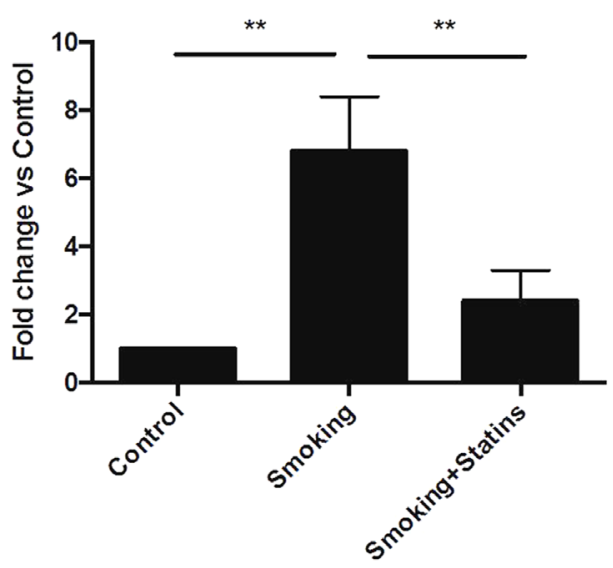

B. Protein

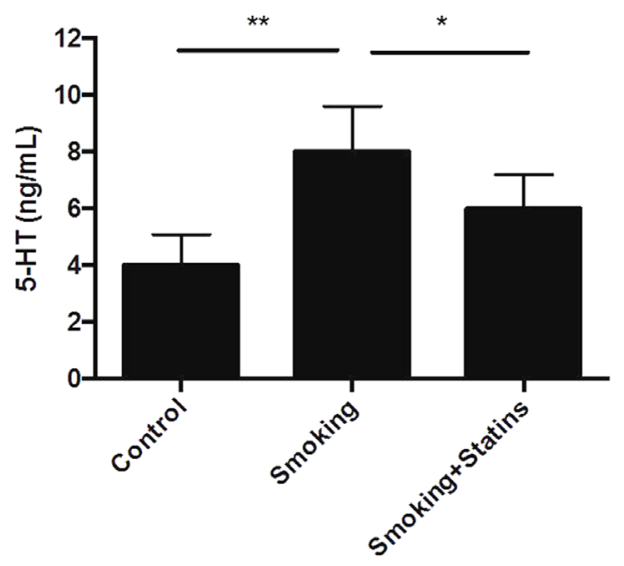

Fig. 5. Expression of 5-HTT mRNA in the lung and 5-HT protein level in blood. (Panel A) Expression of 5-HTT mRNA in the lung. Total RNA was extracted and real time RT-PCR was performed as described in the methods. Vertical axis: 5-HT mRNA expressed as fold change vs control; horizontal axis: treatment group. Data presented was an average of 3 biological replicates. ${ }^{* *} p<0.01$. (Panel B) Level of 5-HT in rat plasma. Protein level of 5-HT in rat plasma was quantified using an ELISA as described in the method. Vertical axis: 5-HT protein $(\mathrm{ng} / \mathrm{mL})$; horizontal axis: treatment group. Data presented was an average of 10 biological replicates. ${ }^{* *} p<0.01 ;{ }^{*} p<0.05$.

Since inflammatory cells may contribute to the pathogenesis of cigarette smokeinduced pulmonary hypertension, the correlationship between BALF inflammatory cell number and parameters of PAH was analyzed. As shown in Fig. 3, the number of leukocytes was significantly correlated with $\mathrm{mPAP}(r=0.739, p=0.000)$, RVHI $(r=0.524, p=0.003)$, WT\% $(r=0.514, p=0.004)$, and WA\% $(r=0.581, p=0.001)$.

\section{Expression of 5-HTT in the lung and level of 5-HT in blood circulation}

Since 5-HT has been reported to play important role in the pathogenesis of PAH [26], gene expression of 5-HTT in the lung was assessed by real time RT-PCR, and protein of 5-HTT was detected by immunohistochemistry of the lung tissue. As shown in Fig. 4, 5-HTT was undetectable in the lung tissue of control group (Fig. 4A). In contrast, 5-HTT was strongly positive in the smoke-exposed rat pulmonary artery endothelium cells and alveolar 


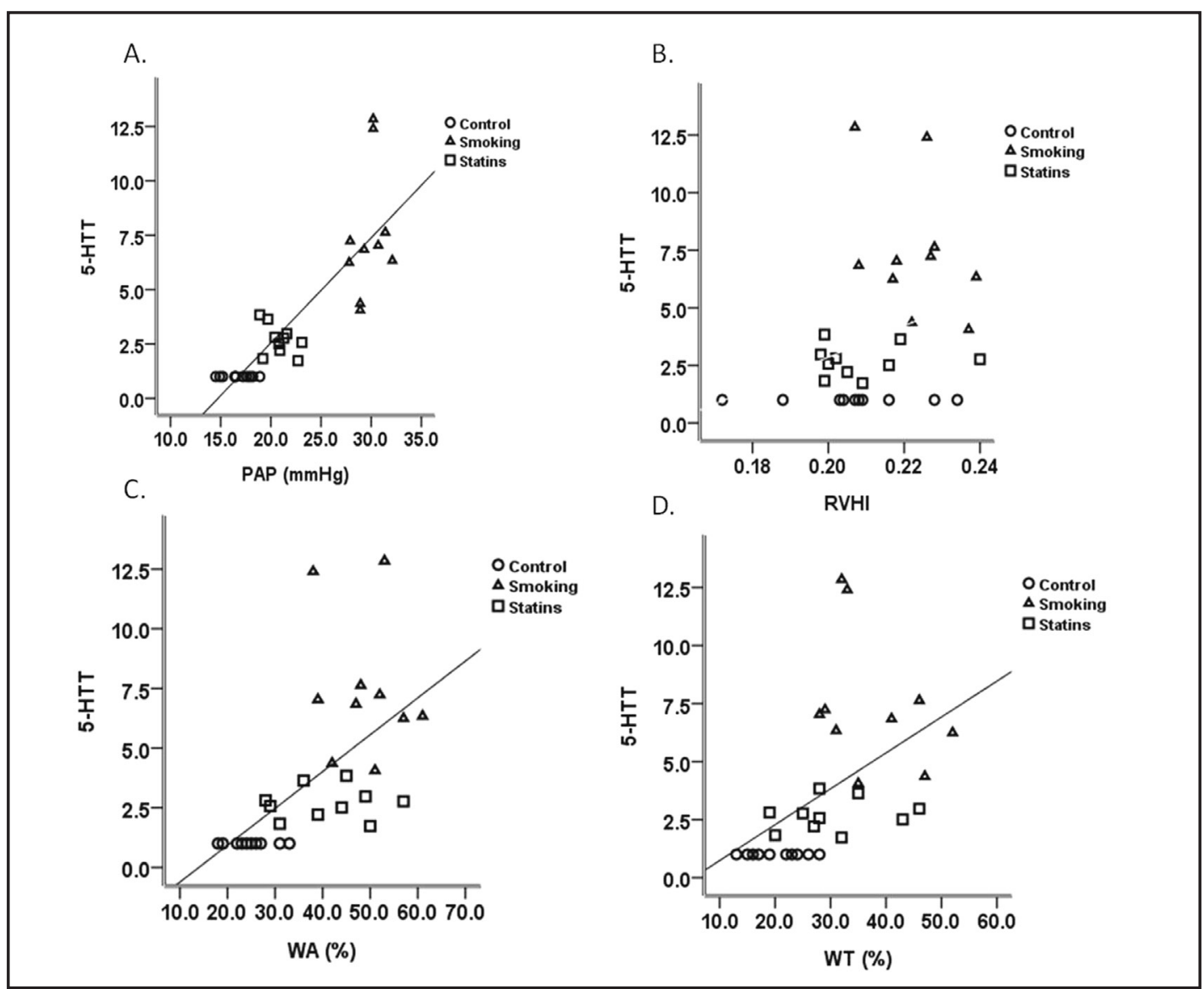

Fig. 6. Correlation between the expression of 5-HT in rat plasma and rat mPAP, RVHI, WA\%, and WT\%. (Panel A) Positive correlation between 5-HT in rat plasma and mPAP ( $r=0.816, p=0.000)$. (Panel B) Positive correlation between 5-HT in rat plasma and RVHI $(r=0.467, p=0.000)$. (Panel C) Positive correlation between 5-HT in rat plasma and WA\% $(r=0.744, p=0.000)$. (Panel D) Positive correlation between 5-HT in rat plasma and $\mathrm{WT} \%(r=0.644, p=0.000) . \mathrm{N}=10$ rats each group.

macrophages (Fig. 4B), and simvastatin treatment resulted in significant decrease 5-HTT expression in the pulmonary arterial endothelium cells and smooth muscle cells (Fig 4C).

Next, gene expression of 5-HTT in the rat lung tissue was assessed by real time RTPCR. As shown in Fig. 5A, expression of 5-HTT mRNA in the smoking group was significantly increased ( $7.43 \pm 3.54$ fold change versus control group, $p<0.01$, Fig. $5 \mathrm{~A})$, and simvastatin could significantly blocked cigarette smoke-induced up-regulation of 5-HTT mRNA (2.81 \pm 0.82 fold change versus control group, $p<0.01$, Fig. $5 \mathrm{~A}$ )

Consistent with alteration of 5-HTT mRNA and protein in the lung tissues, circulating level of 5-HT protein was significantly increased in the smoke-exposed rat $(8.04 \pm 1.32 \mathrm{ng} /$ $\mathrm{mL})$ compared to control rats $(4.04 \pm 0.84 \mathrm{ng} / \mathrm{mL}, p<0.01)$, and it was significantly reduced by simvastatin ( $6.34 \pm 1.17 \mathrm{ng} / \mathrm{mL}, p<0.05$ compared to the smoking group, Fig. $5 \mathrm{~B})$.

Correlationship of 5-HTTor 5-HTand parameters of PAH model

As was shown in Fig. 6, protein level of 5-HTT in the lung tissue had no correlation with RVHI $(r=-0.323, p=0.082)$, but it was significantly correlated with mPAP $(r=0.842$, $p<0.001)$, WT\% $(r=0.486, p=0.006)$, and WA\% $(r=0.5923, p=0.001)$.

Furthermore, protein level of 5-HT showed positive correlation with mPAP $(r=0.816$, $p<0.001)$, RVHI $(r=0.467, p=0.009)$, WT\% $(r=0.644, p<0.001)$, and WA $\%(r=0.744, p<$ 0.001 , Fig. 7). 
A.

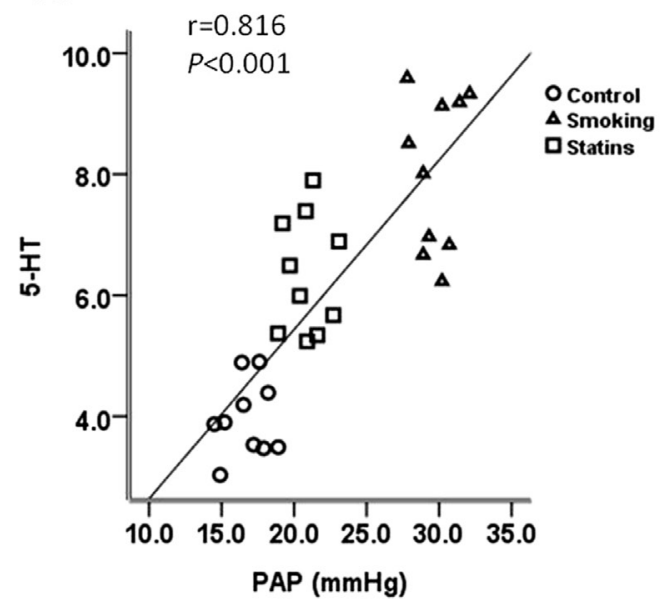

C.

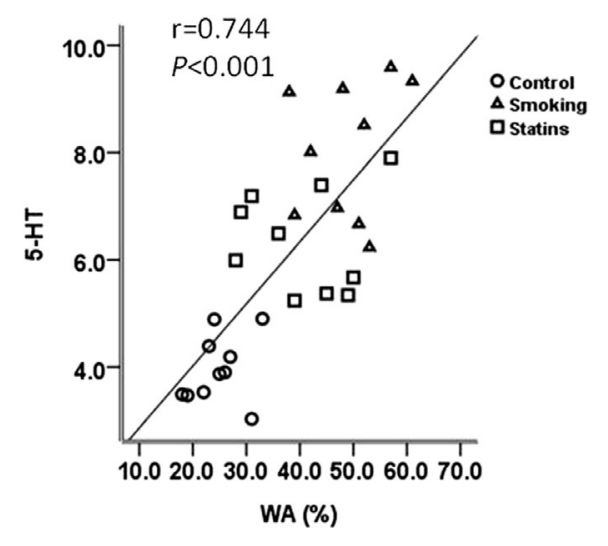

B.

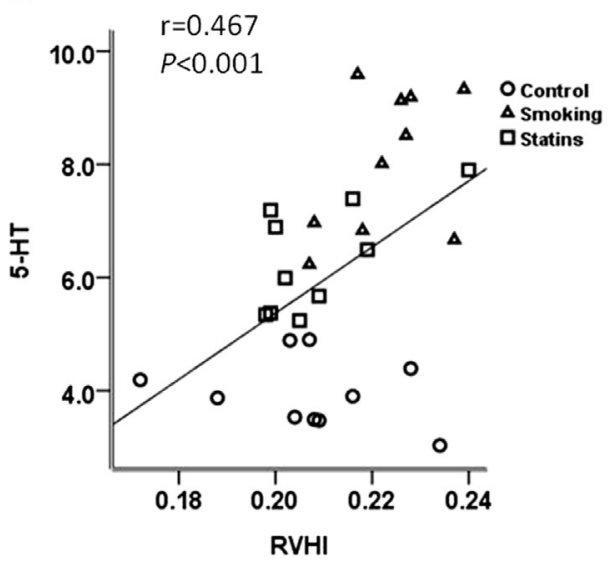

D.

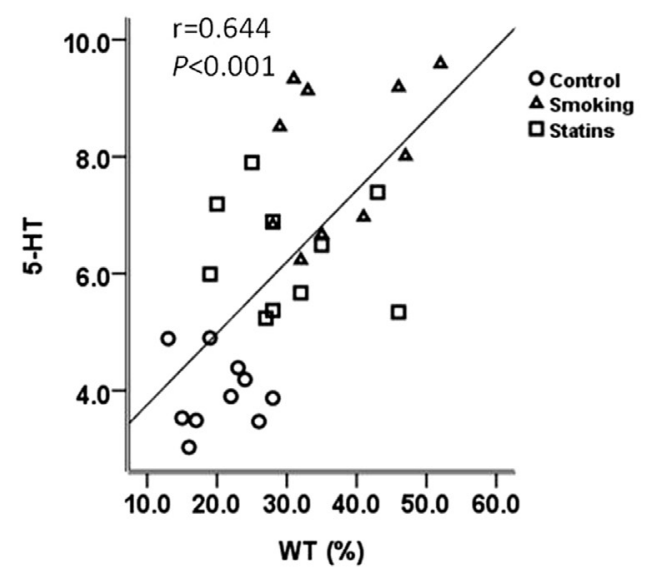

Fig. 7. Correlation between the expression of 5-HTT mRNA in rat lung tissue and PAP, RVHI, WA\%, and WT\%. (Panel A) Positive correlation between 5-HT in rat plasma and mPAP $(r=0.842, p=0.000)$. (Panel B) Positive correlation between 5-HT in rat plasma and RVHI $(r=0.323, p=0.082)$. (Panel C) Positive correlation between 5-HT in rat plasma and WA\% ( $r=0.593, p=0.001)$. (Panel D) Positive correlation between 5-HT in rat plasma and $\mathrm{WT} \%(r=0.486, p=0.006)$. $\mathrm{N}=10$ rats per group.

\section{Discussion}

Numerous animal models of pulmonary artery hypertension (PAH) are currently available. The most commonly used animal models of PAH are the chronic hypoxic model and the monocrotaline injury model [9]. In the current study, however, cigarette smoke exposure was used to prepare $\mathrm{PAH}$ model in rats. Cigarette smoke exposure resulted in not only COPD/emphysema, which has been previously reported by us and other investigators [27-30], but also pulmonary arteriolar wall remodeling and PAH as demonstrated in the current study. Specifically, here, we report that cigarette smoke lead to increase of mean pulmonary arterial pressure (mPAP), right ventricular hypertrophy index (RVHI), arterial wall thickness (WT\%) and wall area (WA\%). Simvastatin could significantly protect rats from cigarette smoke-induced PAH as evidenced by partially reducing mPAP, RVHI, WT\% and WA\%. Cigarette smoke exposure resulted in significant increase of inflammatory cells in the rat BALF, as well as significant up-regulation of 5-HTT in the lung tissue and 5-HT in the blood circulation. Furthermore, total number of BALF leukocytes as well as level of 5-HTT or 5-HT were significantly correlated with PAH parameters including mPAP, RVHI, WT\% and 
WA\%, suggesting inflammatory cells and 5-HTT/5-HT may contribute to the development of PAH in the rats exposed to cigarette smoke. Interestingly, simvastatin could significantly block cigarette smoke-induced infiltration of inflammatory cells into lung tissues as well as up-regulation of 5HTT- and 5-HT, indicating simvastatin may have preventive or therapeutic effect on the development of PAH.

PAH refers to a mean pulmonary artery pressure at rest of greater than or equal to 25 $\mathrm{mm} \mathrm{Hg}$ or greater than $30 \mathrm{~mm} \mathrm{Hg}$ with exercise [31]. To study pathogenesis of PAH, variety types of animal models of PAH have been used. Among them, hypoxia-induced PAH model is the most commonly used model, which is characterized by varying degrees of mild to moderate remodeling of small pulmonary arterioles, adventitial thickening and infiltration by inflammatory cells into the adventitia [32]. While hypoxia-induced PAH animal is useful because it is predictable and reproducible, but the reproducibility is observed only within selected animal strains and the response is also significantly affected by age, as younger individuals with rapidly maturing lungs are more susceptible $[8,33]$. In the current study, therefore, we explored a new PAH model using cigarette smoke exposure. Similar to the hypoxia-induced PAH model, cigarette smoke exposure in the current study could also lead to infiltration of inflammatory cells into alveolar space and thickening of the vascular walls in small pulmonary arterioles. Nevertheless, cigarette smoke exposure could result in not only PAH, but also chronic bronchitis and emphysema [27]. Difference between the hypoxiainduced PAH and cigarette smoke-induced PAH, however, remains to be compared.

It is well known that cigarette smoke exposure could result in COPD and emphysema in animals [28-30]. Consistent with these reports, we have also previously reported that cigarette smoke-exposed rats developed COPD/emphysema characterized by enlarged alveoli (increased mean linear intersection) [27]. In addition to injury of alveoli, the current study further reports that cigarette smoke exposure could also lead to PAH characterized by inflammatory infiltration into adventitia of small arterioles, vascular endothelial dysfunction, and vasoconstriction. Specifically, cigarette smoke resulted in significant increase in mPAP, RVHI, WA\%, and WT\%, which was dramatically blocked by simvastatin. Consistent with previous reports $[23,24]$, the current study demonstrated that simvastatin could significantly inhibited cigarette smoke-induced inflammation of small pulmonary arteries. Furthermore, cigarette smoke-induced animal model of PAH has never been previously reported, and thus, finding of the inhibitory effect of simvastatin on cigarette smoke-induced PAH is novel.

Inflammatory cell numbers and differentials in BALF is an important index that can reflect airway inflammation [34]. In the current study, the total number of inflammatory cells and percentage of neutrophils in BALF were decreased by simvastatin, indicating simvastatin inhibit inflammatory cell accumulation, activation and secretion in the airways and lung tissues. This is consistent with the findings reported by Lee et al. [35].

Although in general, no one animal model of PAH recapitulates all aspects of the severe pathology of human disease [8], these experimental models support the idea that PAH is not so much a specific disease entity as it is a syndrome that may result from a number of disparate pathological states. While pathogenesis of PAH remains to be defined, our results showed that changes in RVHI, WA, WT, mPAP were positively correlated with total cell number and differential cell count in BALF. These results suggested that pulmonary inflammatory infiltration and inflammatory destruction play important role in pulmonary vascular remodeling. Studies have reported that lymphocytes widely reside in small airways and lung parenchyma, including the alveolar wall and artery, and inflammatory cell infiltration is positively correlated to the thickness of pulmonary arterial thickening [36, 37], suggesting that consistent development of small airway inflammation is important not only in COPD, but also inPAH.

The "Serotonin hypothesis of PAH" was developed in the 1960's after an outbreak of $\mathrm{PAH}$ was observed in patients taking aminorex, a diet pill that increases 5-HT availability by inducing platelet release of 5-HT. Normally, 5 -HT is stored within the platelets and thus, plasma levels of free 5-HT are very low. 5-HT is uptaken by the cells specifically through the 5-HT transporter (5-HTT). Circulating 5-HT is produced mainly in the enterochromaffin

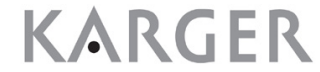




\section{Cellular Physiology Cell Physiol Biochem 2015;37:1712-1724

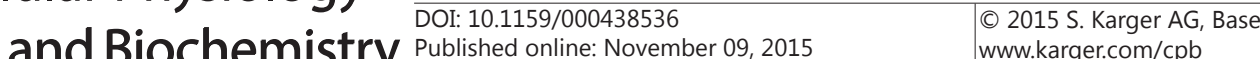 \\ Jiang et al.: Effect of Simvastatin on 5-HT and 5-HTT}

cells of the intestine. Under pathological conditions such as hypoxia, 5-HT is also locally released from pulmonary neuroendocrine cells and epithelial cells [26]. As one of the most important vasoconstriction and mitotic factors, 5-HT induces contraction and proliferation of PASMCs, and by which mechanism, 5-HT may contribute to the development of PAH. In the current study, we found that cigarette smokes significantly increased expression of 5-HT and 5-HTT in the smoking group, and that expression of 5-HT and 5-HTT were positively correlated with WA\%, WT\% and mPAP, indicating 5-HT and 5-HTT maybe associated with pulmonary vascular remodeling and development of PAH. In addition, simvastatin significantly reduced 5-HT and 5-HTT expression, and partially blocked cigarette smokeinduced arterial thickening and lumen contraction. These results suggested that statins could protect pulmonary arterioles from inflammatory injury and remodeling through reducing 5-HT circulation and 5-HTT expression in the lung. Consistently, Laudi et al. reported that atorvastatin significantly inhibited monocrotaline-stimulated 5-HTT and PAH in rat models [38]. However, the mechanism of inhibition of 5-HTT by statin in response to either cigarette smoke exposure or monocrotaline remains to be further investigated although it may be associated with inhibition of Ras homolog gene family member A (RhoA) / Rho-associated, coiled-coil containing protein kinase (ROCK) pathway by statins [39].

Taken together, the current study demonstrated that cigarette smoke exposure resulted in inflammatory cell infiltration into the lung tissue as well as pulmonary arteriole remodeling, which ultimately lead to development of PAH. While mechanism of cigarette smoke-induced PAH remains to be further defined, 5-HT and its transporter (5-HTT) may play an important role in the development of PAH in response to cigarette smoke exposure in the rats. Simvastatin could not only dramatically inhibit inflammatory cells infiltration into the lung and up-regulation of 5-HT/5-HTT in response to cigarette smoke exposure, but also partially blocked pulmonary arteriole wall thickening and wall area enlargement. While the molecular mechanism of inhibitory effect of statin on cigarette smoke-induced 5-HTT up regulation and PAH remains to be further investigated in the future study, findings of current study may provide potential therapeutic target of $\mathrm{PAH}$, specifically, statin regulation on 5-HTT may become a therapeutic strategy in the PAH prevention and treatment.

\section{Disclosure Statement}

All the authors declare that they have no conflict of interest.

\section{References}

1 McGoon MD, Benza RL, Escribano-Subias P, Jiang X, Miller DP, Peacock AJ, Pepke-Zaba J, Pulido T, Rich S, Rosenkranz S, Suissa S, Humbert M: Pulmonary arterial hypertension: epidemiology and registries. J Am Coll Cardiol 2013;62:D51-59.

2 Elliott CG: Genetics of pulmonary arterial hypertension. Clin Chest Med 2013;34:651-663.

3 El Chami H, Hassoun PM: Immune and inflammatory mechanisms in pulmonary arterial hypertension. Prog Cardiovasc Dis 2012;55:218-228.

4 Malenfant S, Neyron AS, Paulin R, Potus F, Meloche J, Provencher S, Bonnet S: Signal transduction in the development of pulmonary arterial hypertension. Pulm Circ 2013;3:278-293.

5 Liu XR, Liu Q, Chen GY, Hu Y, Sham JS, Lin MJ: Down-regulation of TRPM8 in pulmonary arteries of pulmonary hypertensive rats. Cell Physiol Biochem 2013;31:892-904.

6 Chemla D, Humbert M, Sitbon O, Montani D, Herve P: Systolic and mean pulmonary artery pressures: are they interchangeable in patients with pulmonary hypertension? Chest 2015;147:943-950.

7 Lau EM, Humbert M, Celermajer DS: Early detection of pulmonary arterial hypertension. Nat Rev Cardiol 2015;12:143-155. 
8 Stenmark KR, Meyrick B, Galie N, Mooi WJ, McMurtry IF: Animal models of pulmonary arterial hypertension: the hope for etiological discovery and pharmacological cure. Am J Physiol Lung Cell Mol Physiol 2009;297:L1013-1032.

9 Colvin KL, Yeager ME: Animal Models of Pulmonary Hypertension: Matching Disease Mechanisms to Etiology of the Human Disease. J Pulm Respir Med 2014;4:198.

10 Yildiz O, Smith JR, Purdy RE: Serotonin and vasoconstrictor synergism. Life Sci 1998;62:1723-1732.

11 Fanburg BL, Lee SL: A new role for an old molecule: serotonin as a mitogen. Am J Physiol 1997;272:L795806.

12 Robinson MJ, Cobb MH: Mitogen-activated protein kinase pathways. Curr Opin Cell Biol 1997;9:180-186.

13 Lee SL, Wang WW, Fanburg BL: Association of Tyr phosphorylation of GTPase-activating protein with mitogenic action of serotonin. Am J Physiol 1997;272:C223-230.

14 Lee SL, Wang WW, Fanburg BL: Superoxide as an intermediate signal for serotonin-induced mitogenesis. Free Radic Biol Med 1998;24:855-858.

15 Marcos E, Fadel E, Sanchez O, Humbert M, Dartevelle P, Simonneau G, Hamon M, Adnot S, Eddahibi S: Serotonin-induced smooth muscle hyperplasia in various forms of human pulmonary hypertension. Circ Res 2004;94:1263-1270.

16 Eddahibi S, Hanoun N, Lanfumey L, Lesch KP, Raffestin B, Hamon M, Adnot S: Attenuated hypoxic pulmonary hypertension in mice lacking the 5-hydroxytryptamine transporter gene. J Clin Invest 2000;105:1555-1562.

17 Eddahibi S, Humbert M, Fadel E, Raffestin B, Darmon M, Capron F, Simonneau G, Dartevelle P, Hamon M, Adnot S: Serotonin transporter overexpression is responsible for pulmonary artery smooth muscle hyperplasia in primary pulmonary hypertension. J Clin Invest 2001;108:1141-1150.

18 Chang L, Karin M: Mammalian MAP kinase signalling cascades. Nature 2001;410:37-40.

19 Kinlay S: Potential vascular benefits of statins. Am J Med 2005;118:62-67.

20 Sparrow CP, Burton CA, Hernandez M, Mundt S, Hassing H, Patel S, Rosa R, Hermanowski-Vosatka A, Wang PR, Zhang D, Peterson L, Detmers PA, Chao YS, Wright SD: Simvastatin has anti-inflammatory and antiatherosclerotic activities independent of plasma cholesterol lowering. Arterioscler Thromb Vasc Biol 2001;21:115-121.

21 Frenette PS: Locking a leukocyte integrin with statins. N Engl J Med 2001;345:1419-1421.

22 Schonbeck U, Libby P: Inflammation, immunity, and HMG-CoA reductase inhibitors: statins as antiinflammatory agents? Circulation 2004;109:II18-26.

23 Kao PN: Simvastatin treatment of pulmonary hypertension: an observational case series. Chest 2005;127:1446-1452.

24 Nishimura T, Faul JL, Berry GJ, Vaszar LT, Qiu D, Pearl RG, Kao PN: Simvastatin attenuates smooth muscle neointimal proliferation and pulmonary hypertension in rats. Am J Respir Crit Care Med 2002;166:14031408.

25 Scanlon SM, Williams DC, Schloss P: Membrane cholesterol modulates serotonin transporter activity. Biochemistry 2001;40:10507-10513.

26 MacLean MR, Herve P, Eddahibi S, Adnot S: 5-hydroxytryptamine and the pulmonary circulation: receptors, transporters and relevance to pulmonary arterial hypertension. Br J Pharmacol 2000;131:161-168.

27 Wang Y, Jiang X, Zhang L, Wang L, Li Z, Sun W: Simvastatin mitigates functional and structural impairment of lung and right ventricle in a rat model of cigarette smoke-induced COPD. Int J Clin Exp Pathol 2014;7:8553-8562.

28 Kennedy-Feitosa E, Pinto RF, Pires KM, Monteiro AP, Machado MN, Santos JC, Ribeiro ML, Zin WA, Canetti CA, Romana-Souza B, Porto LC, Valenca SS: The influence of 5-lipoxygenase on cigarette smoke-induced emphysema in mice. Biochim Biophys Acta 2014;1840:199-208.

29 Givi ME, Peck MJ, Boon L, Mortaz E: The role of dendritic cells in the pathogenesis of cigarette smokeinduced emphysema in mice. Eur J Pharmacol 2013;721:259-266.

30 Crane-Godreau MA, Black CC, Giustini AJ, Dechen T, Ryu J, Jukosky JA, Lee HK, Bessette K, Ratcliffe NR, Hoopes PJ, Fiering S, Kelly JA, Leiter JC: Modeling the influence of vitamin D deficiency on cigarette smokeinduced emphysema. Front Physiol 2013;4:132.

31 Hoeper MM, Bogaard HJ, Condliffe R, Frantz R, Khanna D, Kurzyna M, Langleben D, Manes A, Satoh T, Torres F, Wilkins MR, Badesch DB: Definitions and diagnosis of pulmonary hypertension. J Am Coll Cardiol 2013;62:D42-50. 


\section{Cellular Physiology Cell Physiol Biochem 2015;37:1712-1724 \begin{tabular}{ll|l} 
and Biochemistry & $\begin{array}{l}\text { DOI: 10.1159/000438536 } \\
\text { Published online: November 09, } 2015\end{array}$ & $\begin{array}{l}\text { () 2015 S. Karger AG, Basel } \\
\text { www.karger.com/cpb }\end{array}$ \\
\cline { 2 - 3 }
\end{tabular} \\ Jiang et al.: Effect of Simvastatin on 5-HT and 5-HTT}

32 Hoshikawa Y, Nana-Sinkam P, Moore MD, Sotto-Santiago S, Phang T, Keith RL, Morris KG, Kondo T, Tuder RM, Voelkel NF, Geraci MW: Hypoxia induces different genes in the lungs of rats compared with mice. Physiol Genomics 2003;12:209-219.

33 Stenmark KR, Fagan KA, Frid MG: Hypoxia-induced pulmonary vascular remodeling: cellular and molecular mechanisms. Circ Res 2006;99:675-691.

34 Yao H, Edirisinghe I, Rajendrasozhan S, Yang SR, Caito S, Adenuga D, Rahman I: Cigarette smoke-mediated inflammatory and oxidative responses are strain-dependent in mice. Am J Physiol Lung Cell Mol Physiol 2008;294:L1174-1186.

35 Lee JH, Lee DS, Kim EK, Choe KH, Oh YM, Shim TS, Kim SE, Lee YS, Lee SD: Simvastatin inhibits cigarette smoking-induced emphysema and pulmonary hypertension in rat lungs. Am J Respir Crit Care Med 2005;172:987-993.

36 Peinado VI, Barbera JA, Abate P, Ramirez J, Roca J, Santos S, Rodriguez-Roisin R: Inflammatory reaction in pulmonary muscular arteries of patients with mild chronic obstructive pulmonary disease. Am J Respir Crit Care Med 1999;159:1605-1611.

37 Maestrelli P, Saetta M, Mapp CE, Fabbri LM: Remodeling in response to infection and injury. Airway inflammation and hypersecretion of mucus in smoking subjects with chronic obstructive pulmonary disease. Am J Respir Crit Care Med 2001;164:S76-80.

38 Laudi S, Trump S, Schmitz V, West J, McMurtry IF, Mutlak H, Christians U, Weimann J, Kaisers U, Steudel W: Serotonin transporter protein in pulmonary hypertensive rats treated with atorvastatin. Am J Physiol Lung Cell Mol Physiol 2007;293:L630-638.

39 Kato T, Hashikabe H, Iwata C, Akimoto K, Hattori Y: Statin blocks Rho/Rho-kinase signalling and disrupts the actin cytoskeleton: relationship to enhancement of LPS-mediated nitric oxide synthesis in vascular smooth muscle cells. Biochim Biophys Acta 2004;1689:267-272. 